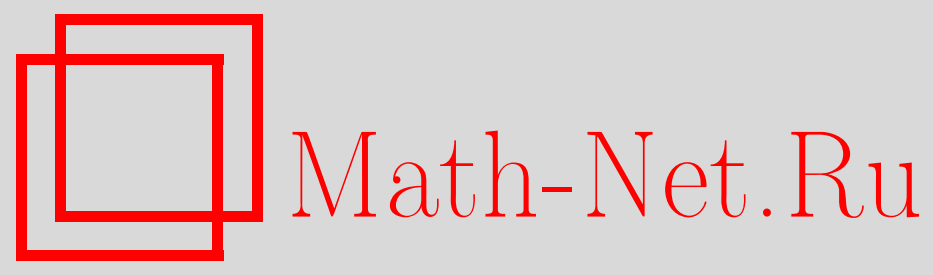

А. Минеев, Дышите на здоровье!, Квант, 2020, номер 4, 29-31

DOI: https://doi.org/10.4213/kvant20200405

Использование Общероссийского математического портала Math-Net.Ru подразумевает, что вы прочитали и согласны с пользовательским соглашением http: //www.mathnet.ru/rus/agreement

Параметры загрузки:

IP : 54.172 .240 .79

26 апреля 2023 г., 10:29:33

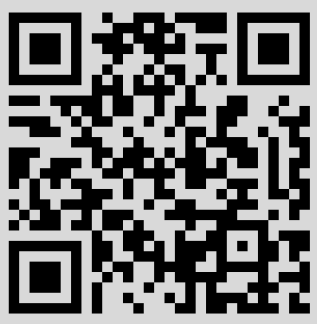




\section{Дышите на здоровье!}

\section{A.MИНEEB}

\section{$\mathrm{B}$} ДАННОЙ СТАТЬЕ РЕЧЬ ПОЙДЕТ О

воздействии на человека кислорода и углекислого газа - по отдельности и вместе. Некоторую настоящую интригу придает взгляд на проблему как извне - со стороны вдыхаемого воздуха, так и изнутри - внутри самого организма. Или, более научно, как со стороны внешнего дыхания - обмена между атмосферой и клетками в легких, так и внутреннего дыхания - процессы в клетках и тканях организма.

Среднее значение давления земной атмосферы на уровне моря примерно равно $p_{\text {атм }}=760$ мм рт. ст. На долю кислорода приходится 160 мм рт. ст. или приблизительно $21 \%$. Кислород частично усваивается организмом, углекислый газ образуется в результате химических реакций окисления. Состав вдыхаемого и выдыхаемого воздуха приведен в таблице.

Таблица 1. Состав вдыхаемого и выдыхаемого воздуха

\begin{tabular}{|l|c|c|c|c|}
\hline & $\mathrm{O}_{2}$ & $\mathrm{CO}_{2}$ & $\mathrm{Ar}$ & $\mathrm{N}_{2}$ \\
\hline $\begin{array}{l}\text { Вдыхаемый } \\
\text { воздух }\end{array}$ & $21 \%$ & $0,04 \%$ & $0,9 \%$ & $78 \%$ \\
\hline $\begin{array}{l}\text { Выдыхаемый } \\
\text { воздух }\end{array}$ & $16 \%$ & $4 \%$ & $0,9 \%$ & $78 \%$ \\
\hline
\end{tabular}

Чем интересны эти цифры? Азот и аргон не используются организмом человека (являются инертными). Степень усвоения кислорода невелика, около 0,25. После вдоха организм выдыхает обратно основную часть кислорода. Углекислый газ практически отсутствует во вдыхаемом воздухе и активно образуется при окислительных реакциях в организме. Процент поглощения организмом кислорода $(21 \%-16 \%=5 \%)$ оказывается близким к проценту образования углекислого газа $(4 \%)$.

DOI: https://doi.org/10.4213/kvant20200405
Инертность азота и аргона при обменных процессах в организме привела к соблазну вообще отказаться от них в условиях длительного пребывания в замкнутом пространстве. По этому пути пошли американские астронавты в первых космических полетах, перейдя на дыхание чистым кислородом. При этом давление в случае использования только $\mathrm{O}_{2}$ было существенно ниже атмосферного и составляло 260-280 мм рт. ст. Однако по мере увеличения длительности космических полетов в такой чисто кислородной атмосфере у астронавтов стали появляться проблемы с дыхательными путями. К тому же, чисто кислородная атмосфера пожароопасна. Российские космонавты с самого начала использовали состав воздуха, близкий к земному, что потребовало более сложной системы регенерации воздуха. В настоящее время при полетах в космосе и в плавании на подводных лодках используется земной состав атмосферы.

\section{Взгляд снаружи}

Диапазон концентрации кислорода в воздухе, пригодный для жизни. Диапазон содержания кислорода в воздухе $p_{\mathrm{O}_{2}}$, при котором возможна жизнедеятельность человека в течение длительного времени, ограничен значениями

$90-100$ мм рт. ст. $<p_{\mathrm{O}_{2}}<400-450$ мм рт. ст.

Нижняя граница соответствует началу кислородного голодания, верхняя - началу кислородного отравления. В процентном отношении наступление кислородного голодания у здорового человека наступает уже при содержании $\mathrm{O}_{2}$ в воздухе $p_{\mathrm{O}_{2}} / p_{\text {атм }}$ менее $14 \%$ (при $p_{\text {атм }}=760$ мм рт. ст.).

Эти данные соответствуют диапазону жизнедеятельности человека на уровне моря. По мере подъема в горы давление снижается, что наглядно отражают кривые атмосферного давления и парциального давления кислорода (рис.1).

Видно, что начиная с высот 4,5-5 км давление кислорода становится ниже допустимой нижней границы давления в 90 мм рт. ст. При этом давление воздуха в альвеолах составляет 105-110 мм рт. ст., что также близко к нижней границе. По мере уменьшения давления кислорода до уровня 


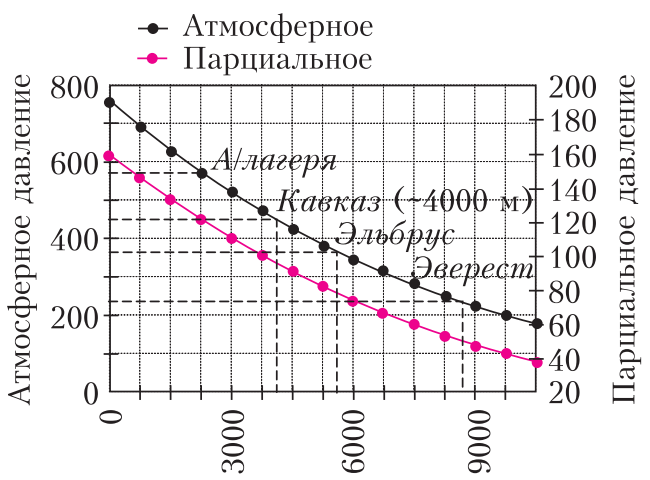

Рис. 1. Зависимость атмосферного давления и парциального давления кислорода (мм рт. ст.) от высоты местности над уровнем моря (метры). Показаны высоты альпинистских лагерей, гор Кавказа, Эльбруса и Эвереста

100 мм рт. ст. замедляются обменные процессы в организме, дыхание и сердцебиение учащаются, ухудшаются зрение и работа мозга... Вот почему высоко в горах люди постоянно жить не могут. В то же время вблизи верхней границы давления кислород начинает раздражать верхние дыхательные пути, появляется сухость в горле, кашель...

Оценка времени развития кислородной недостаточности при нахождении в замкнутом объеме. В качестве примера рассмотрим несколько ситуаций с людьми, находящимися в замкнутом объеме: один человек, застрявший в лифте объемом $V=2$ м $^{3}$; два человека в комнате с $V=30 \mathrm{~m}^{3}$; сто человек, застрявшие в остановившемся вагоне метро с $V=250 \mathrm{~m}^{3}$.

В каждом случае найдем, за какое время $\Delta t$ в замкнутом объеме $V$ в процессе спокойного дыхания людей концентрация кислорода снижается от первоначального уровня 21\% до начала кислородной недостаточности, т.е. до 14\%. Подчеркнем - спокойного, поскольку при панике это время сильно снижается. Спокойному дыханию соответствует потребление кислорода на уровне 0,25 литра в минуту. Поскольку 1 литр $\mathrm{O}_{2}$ соответствует 5 ккал энергии, то 0,25 л/мин сообщает организму за сутки $0,25 \times 5 \times 60 \times 24$ ккал $=$ $=1800$ ккал энергии. Так как плотность человеческого организма около 1000 кг $\mathrm{m}^{3}$, тело массой 70 кг занимает объем $0,07 \mathrm{~m}^{3}$ или 70 литров. Добавив одежду, получим оценку объема, вытесняемого из замкнутого помеще- ния, в 100 литров или 0,1 кубометра на человека.

Лифт. Свободный объем, занятый воздухом, составляет $1,9 \mathrm{~m}^{3}$. В этом объеме содержится $1,9 \times 0,21 \mathrm{~m}^{3}=0,4 \mathrm{~m}^{3}=400$ л кислорода. Признаки кислородной недостаточности развиваются, когда полезный объем кислорода уменьшится до $1,9 \times 0,14 \mathrm{~m}^{3}=$ $=0,27 \mathrm{~m}^{3}=270$ л. Изменение объема от 400 литров до 270 литров при потреблении кислорода одним человеком 0,25 л/мин займет время $\Delta t_{\mathrm{O}_{2}}=130 / 0,25$ мин $=520$ мин, т.е. более 8 часов.

Комната. Свободный объем около $30 \mathrm{~m}^{3}$. Начальный объем кислорода $6,3 \mathrm{~m}^{3}$. Минимально допустимый объем кислорода $4,2 \mathrm{~m}^{3}$. Потребление кислорода 0,5 л/мин . Время $\Delta t_{\mathrm{O}_{2}}=2100 / 0,5$ мин $=4200$ мин, т.е. почти трое суток (!).

Вагон метро. Свободный объем около $240 \mathrm{~m}^{3}$. Начальный объем кислорода $50 \mathrm{~m}^{3}$. Минимально допустимый объем кислорода $34 \mathrm{~m}^{3}$. Потребление кислорода около 25 л/мин . Время $\Delta t_{\mathrm{O}_{2}}=16000 / 25$ мин $=$ $=640$ мин, т.е. около 10 часов.

Во всех указанных случаях (если нет паники) время развития кислородной недостаточности очень велико. Однако, такой вывод находится в противоречии с житейским опытом: в метро и застрявшем лифте бывает душно и даже после сна в комнате с закрытой форточкой наутро ощущается духота. По всей видимости, имеет место другой, более мощный механизм развития неблагоприятных ощущений в процессе дыхания при нахождении в замкнутом объеме, не связанный с потерей кислорода из воздуха. Оказывается, таким механизмом является накопление углекислого газа.

Концентрация углекислого газа в воздухе, пригодная для жизни. Диапазон допустимого содержания $\mathrm{CO}_{2}$ в воздухе составляет

$$
0<C_{\mathrm{CO}_{2}}=\frac{p_{\mathrm{CO}_{2}}}{p_{\text {атм }}}<0,1 \% .
$$

Отметим, что обычное содержание углекислого газа в воздухе $C_{\mathrm{CO}_{2}}=0,04 \%$.

Величину принятого ограничения сверху на содержание углекислого газа $\left(C_{\mathrm{CO}_{2 \max }}=0,1 \%\right)$ обсудим чуть позже, а сначала проведем оценки для замкнутых объемов лифта, комнаты, вагона метро и школьного класса 
применительно ко времени накопления концентрации углекислого газа до верхней границы. Примем, что взрослый человек обычно выдыхает углекислого газа в атмосферу $q_{\mathrm{CO}_{2}}=0,25$ л/мин.

Лuфm. Свободный объем, занятый воздухом, равен $1,9 \mathrm{~m}^{3}$. Изменение уровня содержания $\mathrm{CO}_{2}$ в воздухе от $0,04 \%$ до $0,1 \%$ займет

$$
\begin{aligned}
& \Delta t_{\mathrm{CO}_{2}}=\frac{\left(C_{\mathrm{CO}_{2 \max }}-C_{\mathrm{CO}_{2}}\right) \cdot V}{q_{\mathrm{CO}_{2}}}= \\
& =\frac{\left(1 \cdot 10^{-3}-4 \cdot 10^{-4}\right) \cdot 1,9 \cdot 10^{3}}{0,25} \text { мин = 5 мин. }
\end{aligned}
$$

Комната. Свободный объем около $30 \mathrm{~m}^{3}$. Изменение уровня содержания $\mathrm{CO}_{2}$ в воздухе от $0,04 \%$ до $0,1 \%$ займет $\Delta t_{\mathrm{CO}_{2}}=$ $=6 \cdot 10^{-4} \cdot 30 \cdot 10^{3} /(2 \cdot 0,25)$ мин $=36$ мин .

Вагон метро. Свободный объем около $240 \mathrm{~m}^{3}$. Изменение уровня содержания $\mathrm{CO}_{2}$ в воздухе от $0,04 \%$ до $0,1 \%$ займет $\Delta t_{\mathrm{CO}_{2}}=$ $=6 \cdot 10^{-4} \cdot 240 \cdot 10^{3} /(100 \cdot 0,3)$ мин $\approx 6$ мин.

Школьный класс. Приведем также оценки для школьного класса объемом около $200 \mathrm{~m}^{3}$, в котором находится 25 учеников. При уровне выдоха $\mathrm{CO}_{2}$ одним школьником 0,12 л/м (половина от взрослого) получим $\Delta t_{\mathrm{CO}_{2}}=$ $=6 \cdot 10^{-4} \cdot 200 \cdot 10^{3} /(25 \cdot 0,12)$ мин $\approx 40$ мин.

Это уже ближе к житейским ощущениям и оправдывает присутствие вентиляции на потолке лифтов, необходимость проветривания комнат в домах, в школьных классах после каждого урока, а также наличие системы вентиляции в метро.

Таким образом, именно накопление углекислого газа в замкнутых помещениях в первую очередь действует угнетающе на человека. В чем это проявляется?

В литературе отмечается два типа воздействия: кратковременное (часы) и длительное (регулярно, более нескольких часов в день). Симптомы при кратковременном воздействии при уровне вдыхаемого углекислого газа выше 0,1\% - это усталость, головная боль, ухудшение концентрации внимания, плохой сон... При длительном воздействии при уровне $\mathrm{CO}_{2}$ выше $0,1 \%$ появляются проблемы с дыхательной системой (сухой кашель, риниты...), снижение иммунитета, ухудшение работы сердечно-сосудистой си- стемы... При уровне выше 0,2\% еще больше ухудшается концентрация внимания, растет количество совершаемых ошибок и т.д. по нарастающей. Возможно, требуется более жесткое ограничение на допустимый уровень $\mathrm{CO}_{2}$ во вдыхаемом воздухе - порядка $0,06-0,08 \%$. Это еще сильнее ограничит длительность нахождения в помещениях без вентиляции.

Еще одна проблема помещений без вентиляции - возможность расслоения воздуха на фракции. Поскольку углекислый газ в полтора раза тяжелее воздуха, он может опуститься ближе к полу и его концентрация там увеличится. Но процесс этот медленный, и любое движение воздуха перемешивает фракции.

Наконец, использование растений, казалось бы, должно помочь - ведь они выделяют кислород и поглощают углекислый газ. Однако, это происходит только днем, а вечером и ночью (когда свежий воздух особенно нужен) растения выделяют углекислый газ, усугубляя проблему с его накоплением.

Накопление угарного газа в замкнутом помещении. Казалось бы, откуда взяться угарному газу (CO) в замкнутом помещении, если нет рядом дровяной печки или камина с неидеальной вытяжкой? Но в литературе приводятся следующие данные: наряду с углекислым газом человек выдыхает также и угарный газ - в количестве примерно 1,6 мл/ч (при нормальных условиях); предельно допустимая для человека концентрация угарного газа составляет $1 \mathrm{M \Gamma} / \mathrm{M}^{3}$.

Этих данных достаточно, чтобы снова провести оценки времени накопления предельной концентрации угарного газа для людей в лифте, комнате, вагоне метро и школьном классе. Для этого перейдем от объема к массе образовывающегося угарного газа, воспользовавшись известным соотношением: один моль любого газа при нормальных условиях занимает объем 22,4 л. Для СО молярная масса равна 28 г, поэтому 1 мл СО имеет массу 1,25 мг, а значит, 1, 6 мл/ч выдыхаемого СО одним человеком соответствует появлению в воздухе 2 мг/ч угарного газа.

В таблице 2 приведены значения времени накопления $\mathrm{CO}_{2}$ и $\mathrm{CO}$ до опасной концен-

(Продолжение см. на с. 34) 
(Начало см. на с. 29)

трации, а также времени развития кислородной недостаточности в лифте, комнате, вагоне метро и школьном классе. Для детей принята половинная величина выдыхаемого $\mathrm{CO}$ и $\mathrm{CO}_{2}$.

Таблица 2. Сопоставление времени снижения концентрации $\mathrm{O}_{2}$, накопления $\mathrm{CO}$ и $\mathrm{CO}_{2}$

\begin{tabular}{|l|c|c|c|c|c|}
\hline & $\begin{array}{c}\text { Кол-во } \\
\text { чел. }\end{array}$ & $\begin{array}{c}\text { Объем, } \\
\mathrm{m}^{3}\end{array}$ & $\begin{array}{c}\text { Время } \\
\downarrow \mathrm{O}_{2}\end{array}$ & $\begin{array}{c}\text { Время } \\
\uparrow \text { СО }\end{array}$ & $\begin{array}{c}\text { Время } \\
\uparrow \mathrm{CO}_{2}\end{array}$ \\
\hline Лифт & 1 & 1,9 & 8 часов & 1 час & 5 минут \\
\hline Комната & 2 & 30 & 3 суток & 13 часов & 36 минут \\
\hline Вагон метро & 100 & 240 & 10 часов & $\approx 1$ час & 6 минут \\
\hline Класс & 25 & 200 & & 8 часов & 40 минут \\
\hline
\end{tabular}

Видно, что накопление углекислого газа примерно на порядок опаснее накопления угарного газа и еще на порядок опаснее снижения концентрации кислорода.

Мощность систем вентиляции. Как оценить мощность систем вентиляции $q_{\text {вент }}$, необходимую для поддержания нормального состава воздуха? Если отвлечься от переходных процессов установления и выравнивания потоков воздуха, то конечный результат выглядит очень просто:

$$
q_{\text {вент }}=\frac{q_{\mathrm{CO}_{2}}}{\left(C_{\mathrm{CO}_{2} \max }-C_{\mathrm{CO}_{2}}\right)} .
$$

Так если $q_{\mathrm{CO}_{2}}=0,25$ литра в минуту (в этом случае человек выдыхает 15 литров $\mathrm{CO}_{2}$ в час), то при $C_{\mathrm{CO}_{2} \max }=1 \cdot 10^{-3}$ и $C_{\mathrm{CO}_{2}}=4 \cdot 10^{-4}$ получим требуемую мощность вентиляции в 420 литров воздуха в минуту или 25 м $^{3}$ в час.

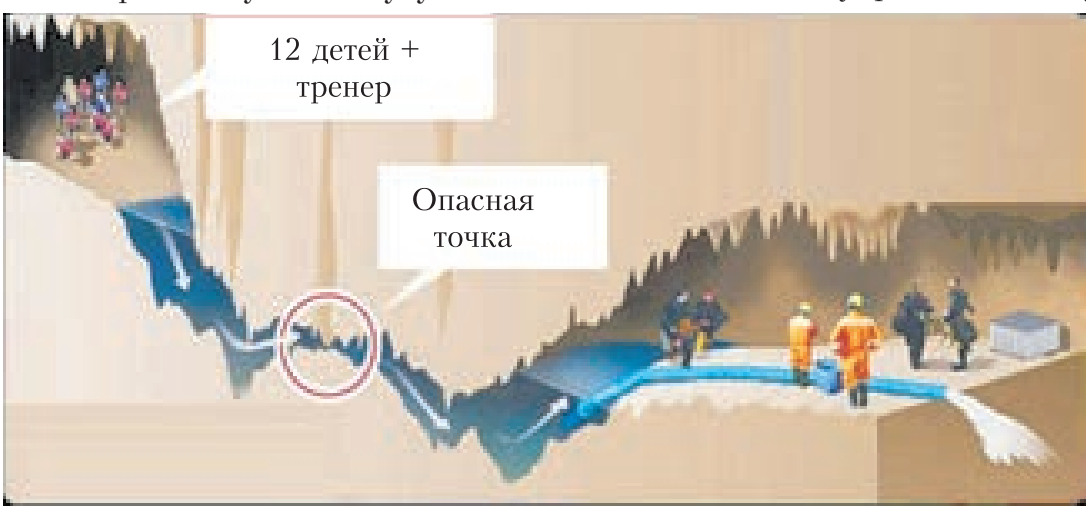

Рис. 2. Характерный вид пещеры Кхао Луанг. Слева - школьники и тренер, запертые в воздушной полости, справа - спасатели
Если же выдыхается 20 литров $\mathrm{CO}_{2}$ в час, то мощность вентиляции увеличивается до $33 \mathrm{~m}^{3}$ воздуха в час. А если принять для максимально допустимого значения концентрации $\mathrm{CO}_{2}$ в воздухе несколько меньшее значение $0,8 \cdot 10^{-3}$, то мощность вырастет уже до 38 м $^{3}$ воздуха в час (при 15 л $\mathrm{CO}_{2}$ в час) и $50 \mathrm{~m}^{3}$ воздуха в час (при 20 л $\mathrm{CO}_{2}$ в час).

Много это или мало? Как обеспечить такой приток свежего воздуха? Например, если приоткрыть дверь, то через каждый квадратный сантиметр щели при перепаде давлений по обе стороны двери $\Delta p=10$ Па проходит в час один кубометр воздуха. Это означает, что при указанном $\Delta p$ через сантиметровую щель в двери высотой два метра проходит $200 \mathrm{~m}^{3}$ воздуха за час. Отметим, что принятый уровень перепада давлений 10 Па довольно мал (это $10^{-4}$ от атмосферного) и вполне может быть достигнут. Еще более мощный эффект вентиляции оказывает проветривание при открытии окон и дверей в течение хотя бы нескольких минут.

В качестве примера рассмотрим ситуацию с кислородом и углекислым газом при спасении детей в пещере Таиланда, частично затопленной водой. В 2018 году весь мир следил за спасением футбольной команды из 12 школьников и их тренера, ушедших на экскурсию в пещеру Кхао Луанг и застрявших в ней на 18 дней (23 июня - 10 июля) из-за дождей, затопивших вход в пещеру. Они укрылись в воздушном кармане, полностью перекрытом водой и удаленном от выхода из пещеры на 5 километров. Задача заключалась в высвобождении ослабевших детей и тренера из пещеры. Ситуация осложнялась наличием узкой щели - на рисунке 2 она обозначена как «опасная точка», через которую предстояло выбираться. Особенно- 


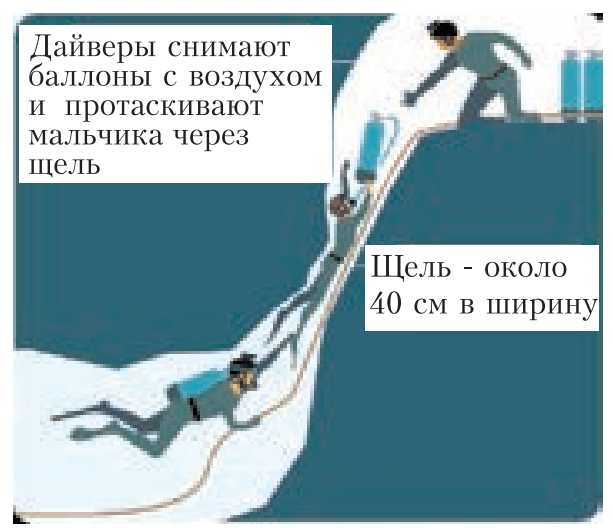

Рис. 3. Узкая щель ("опасная точка»). Для проплыва через щель было необходимо снять акваланг, поэтому каждого ребенка спасали два дайвера

сти проплыва через щель показаны на рисунке 3. Спасателям пришлось непрерывно откачивать воду из пещеры. Поэтому в ней находилось большое количество спасателей, помогавших откачивать воду и готовить детей к выходу.

В этой ситуации оказались важны все отмеченные выше особенности поведения кислорода и углекислого газа в замкнутом объеме. Для борьбы с постепенным уменьшением количества кислорода в пещере была организована доставка кислорода с помощью специального трубопровода. Было решено, что накопление углекислого газа в пещере представляет существенно большую опасность, чем нехватка кислорода. Закачкой кислорода по трубопроводу в верхнюю часть пещеры вытесняли углекислый газ. Учитывалось также расслоение воздуха на фракции $-\mathrm{CO}_{2}$ скапливался в нижней части пещеры. Вот почему дети и тренер скрылись в верхней ее части.

Поиски ребят и подготовительные работы заняли почти две недели. За это время известный изобретатель и организатор исследований Илон Маск (космические корабли, электрокары) успел из запчастей к ракете изготовить миниатюрную подводную лодку на одного человека и доставить ее в Таиланд. Но из-за узкой щели от ее использования отказались.

Ситуация с каждым днем становилась все более сложной. Необходимо было постоянное присутствие людей, занятых на откачке воды из пещеры (иначе пещера полностью заполнилась бы водой) и установке труб для подачи кислорода. Более десятка аквалангистов доставляли в пещеру воду, еду и кислородные баллоны. Там постоянно присутствовали врачи и те, кто готовили спасательную операцию. При дыхании этих взрослых спасателей состав воздуха ухудшался еще стремительнее. Наступил момент, когда из-за накопления углекислого газа дальше ждать было нельзя. Множество кислородных баллонов было расставлено по всему маршруту из пещеры к выходу (каждый баллон рассчитан на работу только в течение часа). Тысяча спасателей снаружи, включая сто дайверов, начали операцию. В первый день 13 дайверов спасли четырех подростков. Во второй день 18 дайверов (и 70 аквалангистов сопровождения) спасли еще четверых. Наконец, в третий день были спасены оставшиеся четверо детей и их тренер, а также 4 человека, остававшиеся в пещере. Молодцы!

\section{Взгляд изнутри}

На уровне клеток организма состав воздушной среды совершенно иной. Содержание кислорода в клетках организма около 1$2 \%$ (исключение - эритроциты, в которых может содержаться до 96-98\% кислорода), углекислого газа в клетках около 6\%. Если концентрации $\mathrm{CO}_{2}$ в клетках уменьшается, то появляется все больше проблем с дыханием. На рисунке 4 приведена зависимость характерного времени, в течение которого человек (не рекордсмен) способен задержать дыхание, частоты пульса и степени

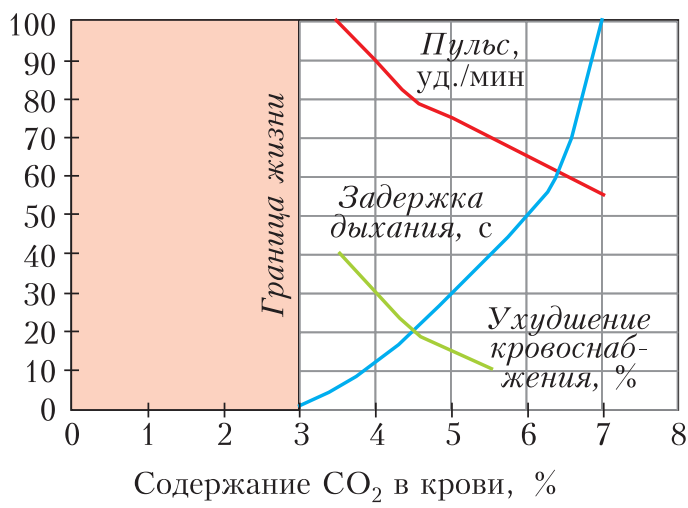

Рис. 4. Характерная зависимость времени задержки дыхания (секунды), частоты пульса (количество ударов в минуту) и степени ухудшения кровоснабжения (проценты) от концентрации углекислого газа в крови 
ухудшения кровоснабжения органов от концентрации углекислого газа. Общий вывод таков: при уменышении концентрации $\mathrm{CO}_{2}$ время задержки дыхания уменьшается и, если она приближается к $3 \%$, клетки гибнут; быстро растет частота пульса; ухудшается кровоснабжение органов. В результате желательная концентрация $\mathrm{CO}_{2}$ в клетках должна быть $6 \%$ и даже немного больше. Примерное содержание кислорода и углекислого газа в различных частях организма человека, приведенное в таблице 3, подтверждает вышеуказанные цифры.

Таблица 3. Содержание кислорода и углекислого газа

\begin{tabular}{|l|c|c|}
\hline & $\mathrm{O}_{2}$ & $\mathrm{CO}_{2}$ \\
\hline $\begin{array}{l}\text { Вдыхаемый } \\
\text { воздух,\% }\end{array}$ & 21 & 0,04 \\
\hline $\begin{array}{l}\text { Выдыхаемый } \\
\text { воздух,\% }\end{array}$ & 16 & 4 \\
\hline $\begin{array}{l}\text { Альвеолярный } \\
\text { воздух, мм рт.ст }\end{array}$ & $105-110(14 \%)$ & $40(5 \%)$ \\
\hline $\begin{array}{l}\text { Артериальная } \\
\text { кровь,мм рт.ст. }\end{array}$ & 100 & 40 \\
\hline $\begin{array}{l}\text { Венозная } \\
\text { кровь,мм рт.ст. }\end{array}$ & 40 & 46 \\
\hline $\begin{array}{l}\text { Клетки, } \\
\text { мм рт.ст. }\end{array}$ & $\sim 10$ & $60-70$ \\
\hline
\end{tabular}

В легких происходит обмен кислорода и углекислого газа между альвеолами и кровью. Альвеолы - концевые образования в легких, имеющие вид пузырьков, которые

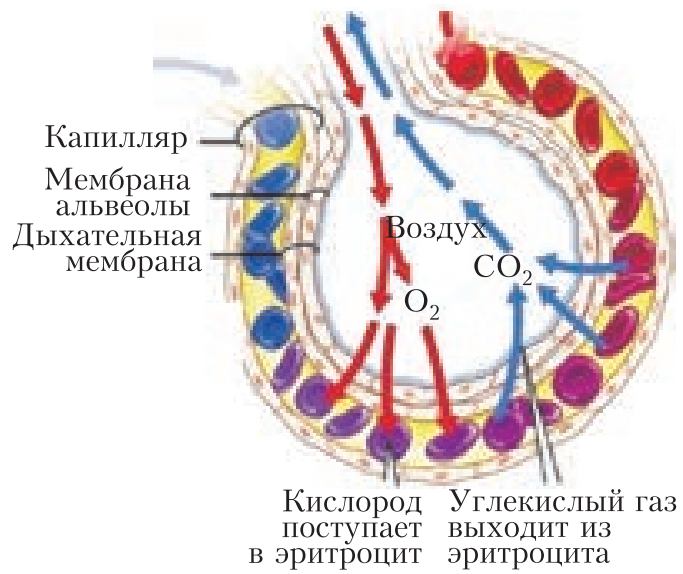

Рис. 5. Вид альвеолы, опутанной капиллярами. Показаны пути поступления кислорода в эритроциты и выхода углекислого газа из эритроцитов оплетены сетью капилляров (рис.5). Через стенки альвеол (их диаметр около 0,3 мм, количество альвеол в легких человека около миллиарда, а общая поверхность приблизительно $100 \mathrm{~m}^{2}$ ) осуществляется газообмен: кислород переходит в кровь и примерно столько же углекислого газа из крови поступает в легкие. Более точно, в среднем за сутки из альвеолярного воздуха в кровь поступает 500 литров кислорода и выделяется 430 литров углекислого газа из крови в альвеолярный воздух.

Более подробно о свойствах альвеол рассказано в книге К.Ю.Богданова «Физик в гостях у биолога» (Библиотечка «Квант», выпуски 49, 133).

\section{Что первично для организма: $\mathrm{O}_{2}$ или $\mathrm{CO}_{2}$ ?}

Помните известный парадокс: что было раньше - курица или яйцо? Он не разрешим, если не привлекать во внимание процесс эволюции и образование новых видов. Но если привлечь, то у яйца оказывается некоторый приоритет, он древнее. Так, еще динозавры откладывали яйца, а птицы произошли от одной из ветвей динозавров. Получается, что яйцо древнее птицы и в этом, эволюционном, смысле первично...

В нашем случае проблема выбора - что первично (иными словами, что запускает процессы в человеческом организме): кислород или углекислый газ - решается следующим образом. Раньше первичным считался кислород - ведь он основной источник энергии, дающий толчок всем процессам в организме. Но сейчас маятник выбора качнулся в сторону углекислого газа. Постепенно пришли к выводу, что первичным, запускающим, механизмом является накопление в организме углекислого газа.

Накопление $\mathrm{CO}_{2}$ в организме в ходе расщепления в клетках жиров и белков дает сигнал мозгу о том, что углекислый газ нужно выводить из клеток - он «садится» на эритроциты и перемещается к альвеолам легких. На освободившиеся места в «поезде» эритроцитов «усаживается» $\mathrm{O}_{2}$ и разносится по организму. Поэтому современный взгляд на процесс дыхания таков: сначала выдыхается углекислый газ, а потом вдыхается кислород. При этом вместе с углекислым газом выдыхаются и излишки кислорода. 
Для дыхания необходимы оба газа, попеременно «седлающие» эритроциты. При этом венозная кровь окрашена с помощью углекислого газа в темно-красный цвет, а артериальная кровь с помощью кислорода - в яркокрасный.

Среднее соотношение между количеством углекислого газа и кислорода в организме здорового человека примерно $3: 1\left(6 \% \mathrm{CO}_{2}\right.$ и $\left.2 \% \mathrm{O}_{2}\right)$.

\section{Взаимодействие «снаружи» и «изнут-}

ри». Итак, углекислый газ необходим для жизнедеятельности человека. Важно и поддержание определенного уровня $\mathrm{CO}_{2}$ в организме. А его недостаток и избыток вредны. Слишком высокое накопление $\mathrm{CO}_{2}$ возможно в плохо проветриваемых помещениях: при большом проценте (более $0,08-0,1 \%$ ) его уровень в организме также растет (последствия этой ситуации обсуждались выше). Нехватка углекислого газа в крови (менее $4 \%)$ тоже опасна (см. рис.4).

В каких случаях может возникнуть такая нехватка? Типичный пример - учащенное дыхание: слишком много $\mathrm{CO}_{2}$ выдыхается и мало остается в организме. При недостатке углекислого газа кислород прочно «прикреплен» к эритроцитам. И даже когда кислорода в крови много, он оказывается связанным и плохо поступает в ткани организма. Если в такой ситуации дышать еще чаще, то это только усугубит ситуацию.

Что делать? Движение, гимнастика, спорт на воздухе или в хорошо проветриваемом помещении - все это увеличивает содержание $\mathrm{CO}_{2}$. Капилляры расширяются и даже образуются новые сети капилляров, кровоток усиливается, кислород лучше отделяется от гемоглобина и поступает в клетки...

Приведем еще один пример важности более редкого дыхания. Стайерам во время бега рекомендуют в случае, когда уже не хватает сил, как можно дольше задержать дыхание для того, чтобы открылось «второе дыхание» и он мог бежать дальше.

Оказание первой помощи. Дыхание «рот в рот». При оказании первой доврачебной помощи человеку в случае исчезновения дыхания одним из действенных методов является искусственное дыхание методом «рот в рот» вместе с непрямым массажем сердца.

В рот пострадавшего через марлю или носовой платок спасатель должен выдыхать воздух с частотой 12-15 раз в минуту. Казалось бы, это бессмысленно. Ведь в начале статьи мы много раз повторяли, каков должен быть состав вдыхаемого воздуха (21\% кислорода и $0,4 \%$ углекислого газа). А тут выходит, что пострадавший вынужден принудительно получать воздух «на выдохе» $\left(16 \% \mathrm{O}_{2}\right.$ и $\left.4 \% \mathrm{CO}_{2}\right)$. Тем не менее, оказывается, что и в выдыхаемом воздухе еще есть остатки кислорода в концентрации, превышающей минимально допустимую (16\% > $>13-14 \%$ ). А большая концентрация $\mathrm{CO}_{2}$ оказывается полезной для стимуляции центра головного мозга, который вызывает дыхательный рефлекс, приводящий к раскрытию альвеол.

В этой ситуации имеется некоторая аналогия с поведением спасателя при остановке сердца: он должен повернуть пострадавшего на спину и нанести ему удар ребром руки по грудной клетке. Цель - сотрясение грудной клетки, что должно привести к запуску остановившегося сердца.

Так что роль $\mathrm{CO}_{2}$ при остановке дыхания несколько иная, чем при обычном, спокойном дыхании.

Способы увеличения концентрации выдыхаемого углекислого газа. Человек в повседневной жизни «в автоматическом режиме» делает примерно 15 циклов вдох-выдох в минуту (каждый цикл имеет длительность приблизительно 4 секунды). Обычное отношение длительности вдоха и выдоха 1 : 1,3.

Смысл основных дыхательных гимнастик заключается в повышении содержания в крови углекислого газа за счет задержки, ослабления, замедления или искусственного затруднения дыхания. При этом повышение концентрации $\mathrm{CO}_{2}$ (до определенного предела, около 8\%) улучшает усвоение кислорода организмом человека. В разных методиках это достигается или за счет задержки дыхания после вдоха либо после выдоха, или за счет удлиненного выдоха, или за счет удлиненного вдоха, или их комбинаций. Иными словами, нужно, чтобы фаза выдоха существенно превышала вдох.

Наиболее последовательной из современных методик является система Бутейко поверхностное дыхание с задержкой. Она направлена на уменьшение потребления кислорода и насыщение организма углекислым газом. По этой системе усилием воли вдох 
занимает 2 секунды, выдох - 4 секунды, за которым следует 4-х секундная задержка дыхания. Всего цикл длится 10 секунд, укладываясь в 6 циклов в минуту.

$\mathrm{B}$ практике йоги правильным считается весьма продолжительный выдох с отношением длительности вдоха и выдоха $1: 5$.

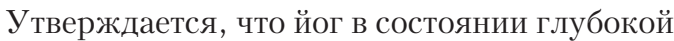
медитации может «обходиться» всего двумятремя циклами вдох-выдох в минуту. Первая реакция на это - не может быть! Но далее неожиданно выясняется, что очень редкое дыхание йогов может быть связано с повышенной ролью у них кожного дыхания.
И действительно, в этом что-то есть. Площадь кожи человека, покрытая 5 миллионами волосков, составляет 1,5-2 м². А суммарная площадь 600 миллионов альвеол в легких - около $100 \mathrm{~m}^{2}$. Грубо получается, что на уровне $1-2 \%$ кожа может выполнять дыхательную функцию. Измерения показали, что через кожу выделяется около $2 \%$ углекислого газа и поглощается примерно 1\% кислорода. Более того, через кожу выводится из организма порядка 800 граммов водяных паров - даже больше, чем из легких!

\section{МА Т Е А Т И Ч С К Й КР УЖ О К}

\section{Об укладке блинов, котлет и апельсинов}

\section{С.ДОРИЧЕНКО}

ЕГОДНЯ КВАНТИК РЕШИЛ СЕРЬезно попрактиковаться в готовке. Сам он обычную пищу не ел, но друзей любил порадовать чем-нибудь вкусненьким.

- Начнем с блинов, решил Квантик. С тестом проблем не возникло, но один блин так причудливо растекся по сковороде, что явно налез бы на другие после переворачивания (рис.1).

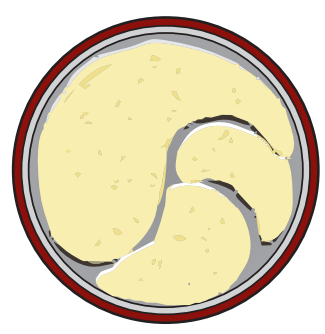

Pис. 1

- Интересно, а поместятся ли блины, если я переверну их все?

Квантик любил сначала все продумать, а потом уже делать. Зачем пытаться уклады-

DOI: https://doi.org/10.4213/kvant20200406 вать перевернутые блины, если они, может, и не влезут? Сначала надо доказать теорему! Но запах подгорающего теста заставил Квантика действовать: он схватил такую же, но холодную сковороду и ловко опрокинул туда все блины, чтобы пока спокойно подумать. Чуть прилипшие блины перевернулись в воздухе целиком вместе с горячей сковородой, но тут же отлипли и аккуратно упали на холодную - румяной стороной кверху.

- Кажется, это было доказательство, осенило Квантика. - Интересно, а если бы моя сковорода была треугольной? Для равностороннего треугольника все бы сработало, а вот для любого... пожалуй, не всегда. (А вы поняли, почему?)

Следующий блин Квантик сделал «математическим», в виде прямоугольника. Переворачивая его на другую сторону, Квантик немного не рассчитал, и прямоугольник завернулся, да так, что даже вылез за пределы сковороды (рис.2).

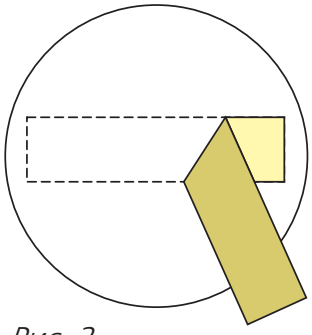

Pnc. 2
- Надо его хотя бы сдвинуть целиком на сковороду. Ой, а вдруг не влезет?

Времени на доказательство не было, и мысли в голове Квантика сменялись с бешеной скоростью. 